\title{
A randomized, double-blind, placebo-controlled study to examine the effects of high-isoflavone soybeans "Yukipirika" in climacteric women
}

\section{Mie Nishimura1, Miwako Sugawara ${ }^{2}$, Masafumi Kudo², and Jun Nishihira ${ }^{1}$}

${ }^{1}$ Department of Medical Management and Informatics, Hokkaido Information University, Ebetsu, Hokkaido, 069-8585, Japan; ${ }^{2}$ Northern Advancement Center for Science \& Technology, Sapporo 001-0021, Japan

Corresponding Author: M.D., Ph.D. Jun Nishihira, Department of Medical Management and Informatics, Hokkaido Information University, Nishi Nopporo 59-2, Ebetsu 069-8585 Hokkaido, Japan

Submission Date: April $18^{\text {th }}$, 2017, Acceptance Date: August $27^{\text {th }}$, 2017, Publication Date: August $31^{\text {st }}, 2017$

Citation: Nishimura M, Sugawara M, Kudo M, and Nishihira J. A randomized, double-blind, placebo-controlled study to examine the effects of high-isoflavone soybeans "Yukipirika" in climacteric women. Functional Foods in Health and Disease 2017; 7(8); 637-660. https://doi.org/10.31989/ffhd.v7i8.359

\footnotetext{
ABSTRACT

Background: Soy isoflavones belong to a class of plant-based compounds known as phytoestrogens and effect menopausal symptoms and bone metabolism. We evaluated the effects of high-isoflavone soybeans ("Yukipirika") in climacteric women.
}

Methods: In this randomized, double-blind, placebo-controlled study, we randomly selected 64 female subjects (aged 46-60 years) to consume products made from high-isoflavone soybeans (active test), low-isoflavone soybeans (Placebo 2), or wheat (Placebo 1). The simplified menopausal index (SMI) test, visual analog scale (VAS) of skin and hair conditions, joints functions, and bowel movements, blood examination, and urinalysis were performed at weeks 0 , 4 , and 8 during the study period. 
Results: Intake of high-isoflavone soybeans did not change bone metabolism parameters. However, a subsection of the SMI score was improved in the active test food group compared to the Placebo 2 food group. Additionally, VAS of skin conditions, joints functions, and bowel movements improved in the active test group compared to the Placebo 1 or Placebo 2 groups.

Conclusion: These results suggest that the ingestion of high-isoflavone soybeans "Yukipirika" can improve skin conditions, joints functions, and bowel movements, in addition to menopausal symptoms.

\section{Clinical trial registration: UMIN000019450}

Keywords: bone metabolism, clinical trial, isoflavone, soybeans, menopausal symptoms, Yukipirika

\section{INTRODUCTION}

Menopause is a period characterized by metabolic, hormonal, and clinical changes from sexual maturity to old age, caused by a decline in endogenous estrogen $[1,2]$. It has been reported that 136,000 women in Japan suffer from menopausal problems. During this phase, most women suffer from a considerable variety of symptoms. Menopausal symptoms include hot flashes, night sweats, menstrual irregularities, vaginal dryness, depression, nervous tension, palpitations, memory problems, and lack of concentration [3,4]. Menopausal syndrome not only affects a woman's quality of life but can be also associated with other health problems such as cardiovascular disease, Alzheimer's disease, and osteoporosis [5-7]. In particular, osteoporosis increases the risk of fracture, which can result in a bedridden state for elderly people. Hormone therapy is the most effective treatment for menopausal syndrome, but various side-effects have been reported, including an increased risk of breast and ovarian cancer, endometrial hyperplasia and carcinoma, stroke, and venous thromboembolism, especially for long-term therapy [8]. Therefore, climacteric women are interested in supplements and functional foods that have effect menopausal symptoms and bone metabolism.

Phytoestrogens are plant compounds with estrogen-like properties [9]. They have received considerable attention over the last few years because of their potentially preventive roles against a few of today's most prevalent chronic diseases (i.e., cardiovascular disease, 
osteoporosis, and hormone-related cancers) [10]. There is great interest in the use of phytoestrogens, such as isoflavone to treat menopausal symptoms and improve bone metabolism [11, 12]. Menopausal symptoms appear to be experienced less frequently by Asian women compared to American or European women [13]. The Asian diet, which is rich in phytoestrogens, may be a contributing factor for these observations [14]. Additionally, many clinical trials have suggested that isoflavones improve menopausal symptoms and bone metabolism. Isoflavones are found in plants, especially soybeans and their derivative foods, such as tofu and miso.

Soybeans have been consumed for centuries in many Asian countries, and recently, soybean popularity has increased markedly in the United States and other Western countries [15]. It has been reported that soybeans, which contain many bioactive components including isoflavones and soy protein, have numerous health benefits [16]. The "Yukipirika" soybean, which is suitable for cold climates because of its resistance to low temperatures, was bred by the Hokkaido Research Organization (Agricultural Research Department, Tokachi Agricultural Experiment Station, Hakkaido, Japan). Additionally, "Yukipirika" contains 1.3 to 1.5 times more soy isoflavone aglycones than standard cultivar [17]. These facts illustrate that we can provide functional foods with higher isoflavone content more efficiently for climacteric women. Therefore, we can expect further improvements in menopausal symptoms and bone metabolism.

We assessed the efficacy of a high-isoflavone soybean diet on menopausal symptoms and bone metabolism in climacteric women volunteers in an 8-week, randomized, double-blind, placebo-controlled trial.

\section{METHODS}

\section{Study subjects}

We recruited 144 volunteers who had unidentified complaints caused by the climacteric. All volunteers provided written informed consent to participate in this clinical study. Finally, through screening tests we selected 75 female subjects (aged 46-60 years). These included individuals having unidentified complaints caused by the climacteric, whose serum tartrate-resistant acid phosphatase-5b (TRACP-5b) activities were >=309 $\mathrm{mU} / \mathrm{dl}$ and $<=760 \mathrm{mU} / \mathrm{dl}$, and those who were judged by a physician as not requiring hospital treatment for 
menopausal symptoms and osteoporosis. We excluded (1) individuals who were receiving medication for menopausal symptoms, osteoporosis, thyroid disease, or psychiatric disorders; (2) those who were considered to have secondary osteoporosis (due to endocrine disorders, continuous use of steroids, etc.); (3) those with serious cerebrovascular, cardiac, hepatic, renal, or gastrointestinal disease; (4) those who had a major surgical history related to the digestive system; (5) those with unusually high and/or low blood pressure (BP), abnormal hematological data, or serious anemia; (6) those who were regularly taking medicine, functional foods, and/or supplements that would improve menopausal symptoms and bone metabolism; (7) heavy smokers, alcohol addicts, or subjects with irregular lifestyle; (8) those with a severe allergic reaction to foods, particularly soybeans or wheat; and (9) those with other medical reasons, as judged by the principal investigator.

The third-party data center assigned the 75 eligible subjects to the active test, Placebo 1, or Placebo 2 group, stratified by age and t simplified menopausal index (SMI) scores. SMI is a test of menopausal symptoms being experienced [18]. The allocations were computer generated using stratified block randomization.. The third-party data center concealed the assignment information, including the subjects' personal data, keeping it secure for the duration of the trial, so that all staff (i.e., doctors, nurses, clinical research coordinators, and statistical analyzers) had no personal knowledge of the participating subjects. This information was disclosed only after the laboratory and analysis data were fixed and the method of statistical analysis was finalized.

\section{Simplified menopausal Index}

SMI consisted of 10 questions to evaluate (1) hot flashes, (2) sweating, (3) cold intolerance, (4) palpitations and shortness of breath, (5) hyposomnia, (6) irritability, (7) depression, (8) headache, dizziness, or nausea, (9) fatigue, and (10) shoulder stiffness and lower back pain. The subjects chose one answer for each question from four choices: (A) strong symptoms, (B) mild symptoms, (C) weak symptoms, or (D) no symptoms. A perfect score on the test was 100 points, and a reduction of SMI score indicated improvement in menopausal symptoms. We evaluated the total score, in addition to the sum of the score from questions 1 to 4,5 to 8 , and 9 to 10 . Questions 1 to 4 assessed symptoms caused by estrogen reduction, questions 5 to 8 assessed symptoms caused by estrogen reduction or environmental factors, and questions 9 to 10 assessed symptoms shown in all generations, unrelated to menopause. 


\section{VAS Questionnaire}

For the evaluation of the effects of high-isoflavone soybeans on skin and hair conditions, joints functions, and bowl movements, the subjects completed a VAS questionnaire. The VAS questionnaire consisted of 12 questions assessing 1) their Skin blotching, 2) Skin dullness, 3) Skin mat, 4) Skin dryness, 5) Skin acne, 6) Hair volume, 7) Hair shine, 8) Knee pain, 9) Knee rigidity, 10) Defecation regularity, 11) Defecation difficulty, and 12) Defecation satisfaction [19, 20]. Subjects were instructed to make a "cross-mark" on a 100-mm line for addressing each question based on their current health condition. The left end of the line $(0 \mathrm{~mm})$ was defined as the worst condition and the right end $(100 \mathrm{~mm})$ as the best condition. The questionnaire's results were assessed by evaluating the length from the left end to the cross-mark. The increase in the VAS score indicated an improvement for each symptom.

\section{Study Design}

The clinical study was conducted as a double-blind, placebo-controlled trial and was operated in Hokkaido Information University, Health Information Science Research Center (Ebetsu city, Hokkaido, Japan). The examination schedule for this study is shown in Table 1. SMI was performed at weeks 0 (baseline), 4, and 8 after the start of test food ingestion. At all three time points, a medical interview was conducted along with an assessment of vital signs, hematological and biological variables, urinalysis, body composition and visual analog scale (VAS) of skin and hair conditions, joints functions, and bowel movements. To investigate the dose-dependent effects of isoflavone, we asked the subject groups to consume daily (1) $8.5 \mathrm{~g}$ of active soybean flakes (high-isoflavone), containing $29.75 \mathrm{mg}$ of isoflavone aglycones (active test food group), (2) placebo soybean flakes (low-isoflavone), containing $8.5 \mathrm{mg}$ of isoflavone aglycones (Placebo 2 food group), or wheat flakes, non-containing of isoflavone aglycones (Placebo 1 food group) at any time of the day. This intake volume of isoflavone was determined in consideration of the food safety intake guidelines set forth by the Food Safety Commission of Japan. During this study, the subjects were asked not to change their daily activities, including food consumption, medication, and exercises. The primary outcomes were SMI scores, urinary type I collagen cross-linked N-telopeptide (NTx), urinary deoxypyridinoline (Dpyr), and serum TRACP-5b. The secondary outcomes were lipid metabolism [total 
cholesterol (TC), high-density lipoprotein cholesterol (HDL-C), low-density lipoprotein cholesterol (LDL-C), and triglycerides (TG)]; transferrin [unsaturated iron binding capacity (UIBC) and total iron binding capacity (TIBC)]; VAS score of skin and hair conditions, joints functions, and bowel movements; and body composition [body weight (BW), body mass index $(\mathrm{BMI})$, and body fat percentage (BFP)].

Table 1. Examination schedule

\begin{tabular}{|l|c|c|c|c|c|c|}
\hline & $\begin{array}{c}\text { Guidance } \\
\& \\
\text { Agreement }\end{array}$ & Screening & Randomization & week 0 & week 4 & week 8 \\
\hline Date & $\begin{array}{c}\text { Oct. 27-30 } \\
2015\end{array}$ & $\begin{array}{c}\text { Oct. 27-30 } \\
2015\end{array}$ & $\begin{array}{c}\text { Nov. 22 } \\
2015\end{array}$ & $\begin{array}{c}\text { Dec. 8-9 } \\
2015\end{array}$ & $\begin{array}{c}\text { Jan. 5-6 } \\
2016\end{array}$ & $\begin{array}{c}\text { Feb. 2-3 } \\
2016\end{array}$ \\
\hline Medical interview & - & $\circ$ & - & $\circ$ & $\circ$ & $\circ$ \\
\hline Vital-sign measurement & - & $\circ$ & - & $\circ$ & $\circ$ & $\circ$ \\
\hline Physical measurement & - & $\circ$ & - & $\circ$ & $\circ$ & $\circ$ \\
\hline Blood sampling & - & $\circ$ & - & $\circ$ & $\circ$ & $\circ$ \\
\hline Urine sampling & - & - & - & $\circ$ & $\circ$ & $\circ$ \\
\hline SIM questionnaire & - & $\circ$ & - & $\circ$ & $\circ$ & $\circ$ \\
\hline VAS questionnaire & - & - & - & $\circ$ & $\circ$ & $\circ$ \\
\hline Test food intake & - & - & - & $\leftarrow$ & & \\
\hline
\end{tabular}

\section{Preparation of Test Food}

The high-isoflavone soybean, "Yukipirika," used for the active test food in this trial was cultivated in Hokkaido, Japan. The low-isoflavone soybean, "Fukuyutaka," as the Placebo 2 food was cultivated in Aichi, Japan. The wheat used for the Placebo 1 food was cultivated in Hokkaido, Japan. The active food and Placebo 2 food were manufactured under strict quality control at the plant of Asahimatsu Foods Co., Ltd. (Nagano, Japan) in compliance with the Food Sanitation Act (Ministry of Health, Labour and Welfare of Japan). The Placebo 1 food was manufactured under strict quality control at the Nippon Food Manufacturer plant (Hokkaido, Japan) with HACCP certification. The manufacturing process for soybean flakes was the following: high-isoflavone soybeans and low-isoflavone soybeans were braised, spread into a thin layer, and then dried. The manufacturing process of wheat flakes was the following: wheat was braised, spread into a thin layer, and then roasted. Analytical results of the nutrient composition for active test, Placebo 1, and Placebo 2 foods used in this study are provided in 
Table 2. The analysis of nutrient composition was performed by the Japan Food Research Laboratories (Chitose, Japan). The active test, Placebo 1, and Placebo 2 foods were identical in appearance.

\begin{tabular}{|l|c|c|c|}
\hline & Placebo 1 & Placebo 2 & Active test \\
\hline Calories (kcal) & 37.3 & 35.1 & 37.3 \\
Water (g) & 0.4 & 0.7 & 0.4 \\
Proteins (g) & 1.1 & 3.3 & 3.2 \\
Lipids (g) & 0.2 & 1.7 & 1.9 \\
Carbohydrates (g) & 6.7 & 2.3 & 2.5 \\
Ash (g) & 0.1 & 0.4 & 0.4 \\
Sodium (mg) & 0.1 & 0.6 & 0.8 \\
Isoflavone aglycone (mg) & 0 & 8.5 & 29.75 \\
\hline
\end{tabular}

\section{Physical, Urinary, and Hematological Examinations}

Blood was collected after $12 \mathrm{~h}$ of fasting. General blood tests were performed, including measurements of bone metabolism (TRACP-5b), lipids (TG, TC, HDL-C, and LDL-C), transferrin (UIBC and TIBC), hormone [estradiol ( $\left.\mathrm{E}_{2}\right)$ and follicle-stimulating hormone (FSH)], blood glucose [fasting blood glucose (FBG) and hemoglobin A1c (HbA1c)], complete blood counts [CBCs, including white blood cells (WBCs), red blood cells (RBCs), hemoglobin (Hb), hematocrit (Ht), and platelets], liver function [aspartate aminotransferase (AST), alanine aminotransferase (ALT), gamma glutamyl transpeptidase ( $\gamma$-GTP), alkaline phosphatase (ALP), and lactate dehydrogenase (LDH)], and kidney function [blood urea nitrogen (BUN), creatinine (CRE), and uric acid (UA)]. Urinary tests were performed, including measurements of bone metabolism (urinary NTx and urinary Dpyr).

Blood and urinary tests were performed by Sapporo Clinical Laboratory, Inc. (Sapporo, Japan). TRACP-5b was measured using enzyme immunoassay (EIA); transferrin using bathophenanthroline method; hormones using chemiluminescent enzyme immunoassay; FBG and $\mathrm{HbA} 1 \mathrm{c}$ using hexokinase method and latex agglutination test respectively; TG, TC, HDL-C, and LDL-C using free glycerol, cholesterol oxidase, selective inhibition, and selective solubilisation methods respectively; WBCs, RBCs, $\mathrm{Hb}$ level, $\mathrm{Ht}$ and Plt levels using automatic blood cell counting device; FBG and HbA1c using hexokinase method and latex agglutination inhibition assay, respectively; AST, ALT, $\gamma$-GTP, ALP, and LDH using Japan Society of Clinical 
Chemistry (JSCC) reference method; BUN, Cr, and UAC using urease-GLDH method, enzyme assay and uricase-POD method respectively; and urinary NTx and Dpyr using EIA.

Each subject's body composition and BP were measured using a Body Composition Analyzer DC-320 (Tanita Corp, Tokyo, Japan) and an Automatic Blood Pressure Monitor HEM-7080IC (Omron Co., Ltd., Kyoto, Japan) respectively.

\section{Ethics Committee}

All subjects written informed consent prior to undergoing any of the tests related to this study. The Ethics Committee of Hokkaido Information University approved the study protocol in conformity to the Helsinki Declaration (approval date: Sep 30, 2015, approval number: 2015-15). This study was registered with UMIN (approval number: UMIN000019450).

\section{Sample Size}

The sample size was statistically determined to obtain a power of $80 \%$ with an alpha of 0.05 . To demonstrate an effect on SMI at week 8, which was postulated to be a 5-point reduction with a standard deviation (SD) of 5.00, a sample size of 60 (20 in each group) was required. Assuming a $20 \%$ loss in the follow-up rate, 75 subjects were selected.

\section{Statistical Analysis}

Values are presented in the tables as means \pm SD. To analyze the changes among the three groups, we used Kruskal-Wallis test for SMI and VAS scores, and analysis of variance (ANOVA) for other parameters (physical, urinary, hematological, and biological). We also made specific two-group comparisons (active-test vs. placebo-1 and active-test vs. placebo-2) using the Mann-Whitney U test (for SMI and VAS) and Student's t-test (for physical, urinary, hematological, and biological parameters). $p<0.05$ was considered to be significant. Statistical analyses were performed using SPSS Statistics 19 (IBM, Armonk, NY, USA).

\section{RESULTS}

\section{Subject Dropouts, Exclusions, and Characteristics}

During the trial, four subjects withdrew for personal reasons. Consequently, 71 subjects completed this trial (active test food group, $\mathrm{n}=24$; Placebo 1 food group, $\mathrm{n}=23$; Placebo 2 food group, $\mathrm{n}=24)$. Two subjects were excluded from the analysis of the "per protocol set" because of their low ingestion rate (Placebo 2 food group, $n=2$ ). The study flow diagram is shown in Figure 1. The mean age, height, BW, BMI, BFP, SMI score, and serum TRACP-5b for each group are presented in Table 3 . These data did not differ significantly between the active test and Placebo food groups, confirming the appropriate allocation of subjects into the three groups. 


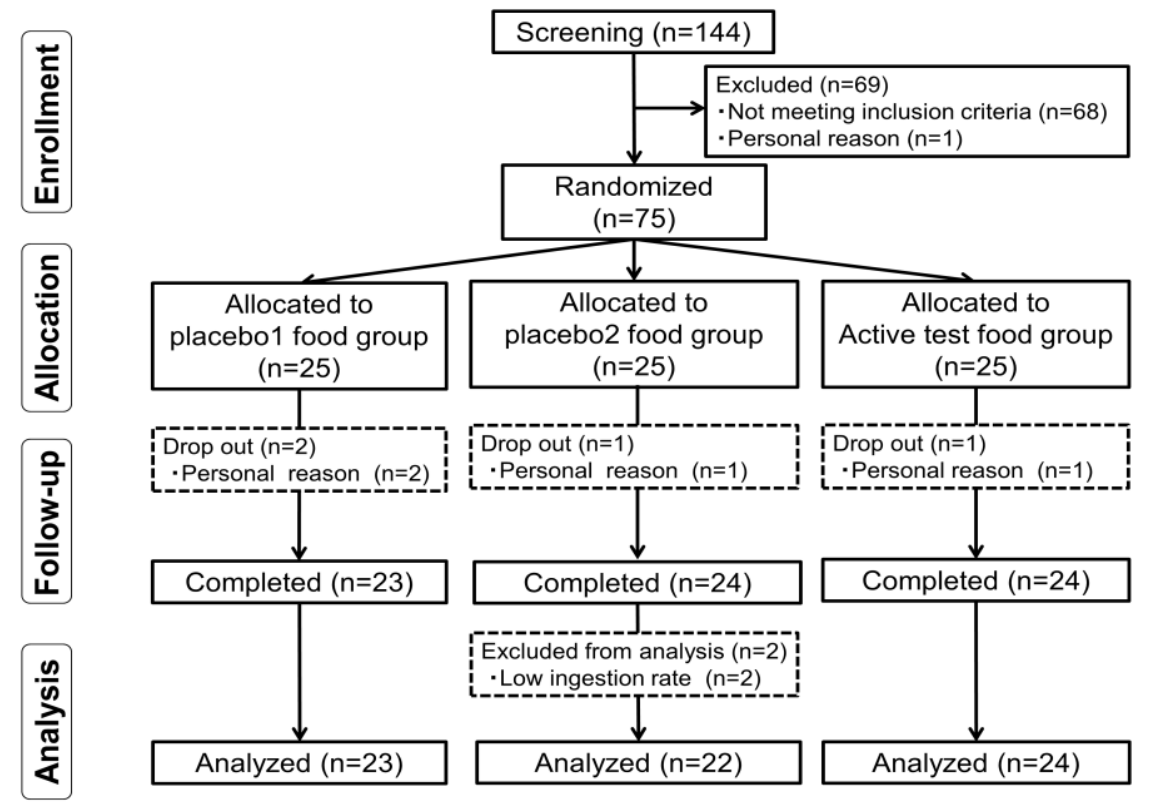

Figure 1. Flow diagram of this trial

Table 3. Characteristics of the subjects in the active test, placebo 1 food, and placebo 2 food groups.

\begin{tabular}{lcccc}
\hline Characteristic & Placebo 1 & Placebo 2 & Active & $p$ \\
\hline Subjects, $n$ & 23 & 22 & 24 & - \\
Age, years & $53.74 \pm 3.62$ & $53.05 \pm 3.53$ & $52.63 \pm 3.32$ & 0.547 \\
Height, cm & $157.38 \pm 4.78$ & $156.99 \pm 4.79$ & $158.02 \pm 5.42$ & 0.781 \\
Body weight, kg & $52.91 \pm 10.61$ & $52.59 \pm 7.03$ & $51.09 \pm 6.22$ & 0.718 \\
Body fat percentage, \% & $21.39 \pm 4.43$ & $21.34 \pm 2.62$ & $20.47 \pm 2.39$ & 0.556 \\
Body mass index, kg/m ${ }^{2}$ & $29.10 \pm 8.13$ & $30.83 \pm 5.81$ & $28.68 \pm 5.15$ & 0.501 \\
Simplified menopausal & $59.67 \pm 19.54$ & $57.50 \pm 17.41$ & $60.38 \pm 16.48$ & 0.853 \\
index, score & & & & \\
Tartrate-resistant acid & $455.35 \pm 125.95$ & $454.86 \pm 90.83$ & $466.46 \pm 96.07$ & 0.913 \\
phosphatase-5b, mU/dl & & & & \\
Intake rate, \% & $98.67 \pm 1.97$ & $97.15 \pm 3.64$ & $97.38 \pm 3.84$ & 0.246 \\
\hline
\end{tabular}

Values are shown as the mean \pm standard deviation. Analyses were performed using one-way ANOVA for age, height, body weight, body fat percentage, body mass index and tartrate-resistant acid phosphatase-5b. The Kruskal-Wallis test was used to analyze, simplified menopausal index and the intake rate. $n$, number of subjects. 


\section{Effects of High-Isoflavone Soybeans on Menopausal Symptoms}

First, we evaluated the effects of high-isoflavone soybeans on menopausal symptom using SMI (Table 4). There were no differences between the active test and Placebo 1 food group or the active test and Placebo 2 food group regarding changes in SMI total scores. However, the values of the SMI sum scores for questions 1 to 4 were decreased in the active test food group compared to the Placebo 2 food group ( $\triangle$ week 8: Placebo 2 score, $-1.11 \pm 4.30$; active score, $-4.63 \pm 5.15 ; \mathrm{p}=0.016$ ).

Table 4. SMI scores

\begin{tabular}{|c|c|c|c|c|}
\hline & & Week 0 & $\Delta$ week 4 & $\Delta \quad$ week 8 \\
\hline \multirow{6}{*}{$\begin{array}{l}\text { SMI total score } \\
\text { (score) }\end{array}$} & Placebo 1 & $57.65 \pm 16.76$ & $-5.22 \pm 12.62$ & $-10.57 \pm 15.83$ \\
\hline & Placebo 2 & $56.89 \pm 15.66$ & $-4.08 \pm 6.62$ & $-5.57 \pm 8.11$ \\
\hline & Active & $58.79 \pm 18.27$ & $-3.54 \pm 10.20$ & $-9.17 \pm 11.75$ \\
\hline & $p^{a}$ & - & 0.52 & 0.48 \\
\hline & $p^{b}$ & - & 0.62 & 0.73 \\
\hline & $p^{c}$ & - & 0.84 & 0.24 \\
\hline \multirow{6}{*}{$\begin{array}{l}\text { SMI sum score of } \\
\text { questions } 1 \text { to } 4 \\
\text { (score) }\end{array}$} & Placebo 1 & $25.43 \pm 7.55$ & $-4.43 \pm 5.83$ & $-5.35 \pm 6.38$ \\
\hline & Placebo 2 & $23.70 \pm 9.06$ & $-1.48 \pm 3.25$ & $-1.11 \pm 4.30$ \\
\hline & Active & $25.96 \pm 7.83$ & $-1.29 \pm 5.94$ & $-4.63 \pm 5.15$ \\
\hline & $p^{a}$ & - & 0.12 & $0.023 *$ \\
\hline & $p^{b}$ & - & 0.07 & 0.67 \\
\hline & $p^{c}$ & - & 0.90 & $0.016^{*}$ \\
\hline \multirow{6}{*}{$\begin{array}{l}\text { SMI sum score of } \\
\text { questions } 5 \text { to8 } \\
\text { (score) }\end{array}$} & Placebo 1 & $22.52 \pm 8.34$ & $-0.65 \pm 6.40$ & $-3.91 \pm 8.73$ \\
\hline & Placebo 2 & $22.64 \pm 8.50$ & $-1.55 \pm 4.61$ & $-3.14 \pm 5.47$ \\
\hline & Active & $22.33 \pm 9.94$ & $-1.17 \pm 5.01$ & $-2.75 \pm 7.05$ \\
\hline & $p^{a}$ & - & 0.98 & 0.74 \\
\hline & $p^{b}$ & - & 0.76 & 0.62 \\
\hline & $p^{c}$ & - & 0.80 & 0.84 \\
\hline \multirow{6}{*}{$\begin{array}{l}\text { SMI sum score of } \\
\text { questions } 9 \text { to } 10 \\
\text { (score) }\end{array}$} & Placebo 1 & $9.70 \pm 3.57$ & $-0.13 \pm 2.70$ & $-1.30 \pm 3.40$ \\
\hline & Placebo 2 & $10.55 \pm 2.94$ & $-1.05 \pm 2.24$ & $-1.32 \pm 2.23$ \\
\hline & Active & $10.50 \pm 3.18$ & $-1.08 \pm 2.55$ & $-1.79 \pm 2.62$ \\
\hline & $p^{a}$ & - & 0.52 & 0.66 \\
\hline & $p^{b}$ & - & 0.22 & 0.58 \\
\hline & $p^{c}$ & - & 0.96 & 0.52 \\
\hline
\end{tabular}

Values are shown as the mean \pm standard deviation. The Kruskal-Wallis test was performed to analyze the changes from the baseline (week 0) to weeks 4 and 8 among the three groups $\left(p^{a}\right)$. Mann-Whitney's U test was performed 
to analyze changes from the baseline (week 0 ) to weeks 4 and 8 between the active test and placebo 1 food groups $\left(p^{b}\right)$, or the active test and placebo 2 food groups $\left(P^{c}\right)$. SMI, simplified menopausal index; $\triangle$ week 4 , change from baseline to week 4 ; $\Delta$ week 8 , change from baseline to week 8 . *Statistically significant, $p<0.05$.

\section{Effects of High-Isoflavone Soybean on Bone Metabolism Parameters}

We also evaluated the effects of high-isoflavone soybeans on bone metabolism parameters (urinary NTx, urinary Dpyr, and serum TRACP-5b). There were no significant differences between the active test and Placebo 1 food groups and the active test and Placebo 2 food groups regarding changes in urinary NTx, urinary Dpyr, and serum TRACP-5b (Table 5).

Table 5. Bone metabolism parameters

\begin{tabular}{|c|c|c|c|c|}
\hline & & Week 0 & $\triangle$ week 4 & $\Delta \quad$ week 8 \\
\hline \multirow{6}{*}{$\begin{array}{l}\text { Serum TRACP-5b } \\
(\mathrm{mU} / \mathrm{dl})\end{array}$} & Placebo 1 & $445.96 \pm 130.79$ & $-4.65 \pm 45.59$ & $12.91 \pm 55.44$ \\
\hline & Placebo 2 & $451.68 \pm 85.87$ & $7.25 \pm 67.96$ & $3.41 \pm 59.39$ \\
\hline & Active & $444.58 \pm 103.64$ & $0.96 \pm 52.61$ & $26.25 \pm 62.21$ \\
\hline & $p^{a}$ & - & 0.78 & 0.42 \\
\hline & $p^{b}$ & - & 0.70 & 0.44 \\
\hline & $p^{c}$ & - & 0.73 & 0.21 \\
\hline \multirow{6}{*}{$\begin{array}{c}\text { Urinary NTx } \\
\text { (nmolBCE/mmolCr } \\
\text { ) }\end{array}$} & Placebo 1 & $67.77 \pm 32.11$ & $-0.02 \pm 27.13$ & $-1.17 \pm 26.70$ \\
\hline & Placebo 2 & $68.52 \pm 21.91$ & $-7.23 \pm 17.82$ & $-1.95 \pm 20.36$ \\
\hline & Active & $64.50 \pm 28.34$ & $4.90 \pm 22.93$ & $10.08 \pm 26.72$ \\
\hline & $p^{a}$ & - & 0.23 & 0.19 \\
\hline & $p^{b}$ & - & 0.51 & 0.16 \\
\hline & $p^{c}$ & - & 0.06 & 0.10 \\
\hline \multirow{6}{*}{$\begin{array}{c}\text { Urinary Dpyr } \\
(\mathrm{nmol} / \mathrm{mmolCr})\end{array}$} & Placebo 1 & $7.65 \pm 1.70$ & $0.58 \pm 1.12$ & $0.66 \pm 0.91$ \\
\hline & Placebo 2 & $7.46 \pm 1.85$ & $0.27 \pm 1.49$ & $0.31 \pm 1.43$ \\
\hline & Active & $6.98 \pm 1.54$ & $0.38 \pm 1.29$ & $0.65 \pm 1.08$ \\
\hline & $p^{a}$ & - & 0.73 & 0.52 \\
\hline & $p^{b}$ & - & 0.57 & 0.99 \\
\hline & $p^{c}$ & - & 0.80 & 0.36 \\
\hline
\end{tabular}

Values are shown as the mean \pm standard deviation. ANOVA was performed to analyze changes from the baseline (week 0) to weeks 4 and 8 among three groups $\left(p^{a}\right)$. Student's t-test was performed to analyze changes from the baseline (week 0) to weeks 4 and 8 between the active test and placebo 1 food groups $\left(p^{b}\right)$, or the active test and placebo 2 food groups $\left(p^{c}\right)$. TRACP-5b, tartrate-resistant acid phosphatase-5b; NTx, type I collagen cross-linked N-telopeptide; Dpyr, deoxypyridinoline; $\triangle$ week 4, change from baseline to week 4; $\triangle$ week 8 , change from baseline to week 8 . *Statistically significant, $p<0.05$. 


\section{Effects of High-Isoflavone Soybeans on VAS Scores}

To confirm the effects of high-isoflavone soybeans on skin/hair condition, joint functions and fecal properties, we evaluated changes in VAS based on a questionnaire rating 12 factors (Table 6). "Skin dryness" was improved after ingestion of the active test food compared to the Placebo 2 food group (change from baseline to week 4: Placebo 2, $0.90 \pm 23.36 \mathrm{~mm}$; active, $7.50 \pm$ $15.66 \mathrm{~mm}, \mathrm{p}=0.010$ ). Additionally, ingestion of the active test food improved "Knee pain" at weeks 4 and 8 compared to the Placebo 1 food group (change from baseline to week 8: Placebo $1,-2.78 \pm 18.31 \mathrm{~mm}$; active, $5.50 \pm 15.60 \mathrm{~mm}, \mathrm{p}=0.031)$ and improved "Knee rigidity" at week 4 compared to Placebo 2 and Placebo 1 food groups (change from baseline to week 4: Placebo 2, $-11.05 \pm 22.32 \mathrm{~mm}$; active, $3.83 \pm 14.07 \mathrm{~mm}, \mathrm{p}=0.047$, change from baseline to week 4: Placebo 1, $-6.09 \pm 11.97 \mathrm{~mm}$; active, $3.83 \pm 14.07 \mathrm{~mm}, \mathrm{p}=0.041$ ). Moreover, "Defecation satisfaction" was improved in the active test food group compared to the findings in the Placebo 2 food group at week 8 (change from baseline to week 8: Placebo 2, $-3.32 \pm$ $16.87 \mathrm{~mm}$; active, $7.00 \pm 16.92 \mathrm{~mm}, \mathrm{p}=0.008)$.

Table 6. VAS score

\begin{tabular}{|c|c|c|c|c|}
\hline & & Week 0 & $\Delta$ week 4 & week 8 \\
\hline \multirow{6}{*}{$\begin{array}{l}\text { Skin blotching } \\
(\mathrm{mm})\end{array}$} & Placebo 1 & $30.48 \pm 24.55$ & $9.09 \pm 17.11$ & $9.00 \pm 15.37$ \\
\hline & Placebo 2 & $30.41 \pm 17.73$ & $3.95 \pm 12.74$ & $5.27 \pm 13.01$ \\
\hline & Active & $30.79 \pm 22.73$ & $3.54 \pm 17.00$ & $3.46 \pm 12.91$ \\
\hline & $p^{a}$ & - & 0.31 & 0.49 \\
\hline & $p^{b}$ & - & 0.19 & 0.26 \\
\hline & $p^{c}$ & - & 0.98 & 0.55 \\
\hline \multirow{6}{*}{$\begin{array}{l}\text { Skin dullness } \\
\quad(\mathrm{mm})\end{array}$} & Placebo 1 & $36.52 \pm 24.67$ & $5.35 \pm 20.66$ & $2.70 \pm 21.64$ \\
\hline & Placebo 2 & $32.91 \pm 19.45$ & $2.05 \pm 18.39$ & $0.77 \pm 11.60$ \\
\hline & Active & $27.46 \pm 20.40$ & $3.58 \pm 14.96$ & $8.58 \pm 17.49$ \\
\hline & $p^{a}$ & - & 0.81 & 0.36 \\
\hline & $p^{b}$ & - & 0.84 & 0.56 \\
\hline & $p^{c}$ & - & 0.69 & 0.13 \\
\hline \multirow{6}{*}{$\begin{array}{l}\text { Skin mat } \\
\text { (mm) }\end{array}$} & Placebo 1 & $32.26 \pm 19.12$ & $6.57 \pm 19.39$ & $5.70 \pm 17.29$ \\
\hline & Placebo 2 & $32.86 \pm 19.10$ & $5.65 \pm 16.95$ & $2.86 \pm 12.38$ \\
\hline & Active & $24.75 \pm 15.95$ & $7.75 \pm 15.18$ & $12.17 \pm 18.05$ \\
\hline & $p^{a}$ & - & 0.89 & 0.14 \\
\hline & $p^{b}$ & - & 0.78 & 0.27 \\
\hline & $p^{c}$ & - & 0.61 & 0.05 \\
\hline Skin dryness & Placebo 1 & $29.91 \pm 17.20$ & $5.26 \pm 22.56$ & $9.91 \pm 25.41$ \\
\hline
\end{tabular}




\begin{tabular}{|c|c|c|c|c|}
\hline & & Week 0 & week 4 & week 8 \\
\hline \multirow[t]{5}{*}{$(\mathrm{mm})$} & Placebo 2 & $34.50 \pm 20.64$ & $0.90 \pm 23.36$ & $-0.41 \pm 18.53$ \\
\hline & Active & $25.79 \pm 21.30$ & $7.50 \pm 15.66$ & $9.30 \pm 21.12$ \\
\hline & $p^{a}$ & - & $0.049 *$ & 0.26 \\
\hline & $p^{b}$ & - & 0.27 & 0.92 \\
\hline & $p^{c}$ & - & $0.010^{*}$ & 0.09 \\
\hline \multirow{6}{*}{$\begin{array}{l}\text { Skin acne } \\
(\mathrm{mm})\end{array}$} & Placebo 1 & $76.09 \pm 23.17$ & $2.57 \pm 15.35$ & $-11.30 \pm 25.74$ \\
\hline & Placebo 2 & $70.77 \pm 28.91$ & $5.15 \pm 23.73$ & $5.23 \pm 21.63$ \\
\hline & Active & $78.13 \pm 22.90$ & $-8.33 \pm 22.65$ & $0.29 \pm 14.59$ \\
\hline & $p^{a}$ & - & $0.041^{*}$ & 0.086 \\
\hline & $p^{b}$ & - & $0.026^{*}$ & 0.12 \\
\hline & $p^{c}$ & - & $0.039^{*}$ & 0.57 \\
\hline \multirow{6}{*}{$\begin{array}{l}\text { Hair volume } \\
\qquad(\mathrm{mm})\end{array}$} & Placebo 1 & $53.43 \pm 28.61$ & $-0.65 \pm 21.41$ & $2.13 \pm 17.66$ \\
\hline & Placebo 2 & $32.32 \pm 31.86$ & $4.90 \pm 19.50$ & $8.05 \pm 26.33$ \\
\hline & Active & $47.67 \pm 31.88$ & $5.04 \pm 14.37$ & $1.54 \pm 12.90$ \\
\hline & $p^{a}$ & - & 0.21 & 0.80 \\
\hline & $p^{b}$ & - & 0.22 & 0.79 \\
\hline & $p^{c}$ & - & 0.27 & 0.55 \\
\hline \multirow{6}{*}{$\begin{array}{l}\text { Hair shine } \\
\qquad(\mathrm{mm})\end{array}$} & Placebo 1 & $46.74 \pm 25.85$ & $-1.52 \pm 19.00$ & $2.61 \pm 17.62$ \\
\hline & Placebo 2 & $29.77 \pm 27.75$ & $5.30 \pm 11.81$ & $5.27 \pm 22.30$ \\
\hline & Active & $35.87 \pm 26.17$ & $1.04 \pm 13.84$ & $3.52 \pm 16.39$ \\
\hline & $p^{a}$ & - & 0.35 & 0.94 \\
\hline & $p^{b}$ & - & 0.53 & 0.73 \\
\hline & $p^{c}$ & - & 0.34 & 0.88 \\
\hline \multirow{6}{*}{$\begin{array}{l}\text { Knee pain } \\
\quad(\mathrm{mm})\end{array}$} & Placebo 1 & $64.30 \pm 32.90$ & $-3.57 \pm 11.49$ & $-2.78 \pm 18.31$ \\
\hline & Placebo 2 & $66.91 \pm 23.04$ & $0.00 \pm 20.42$ & $-0.23 \pm 23.43$ \\
\hline & Active & $65.88 \pm 31.08$ & $7.08 \pm 15.72$ & $5.50 \pm 15.60$ \\
\hline & $p^{a}$ & - & 0.084 & 0.08 \\
\hline & $p^{b}$ & - & $0.022^{*}$ & $0.031^{*}$ \\
\hline & $p^{c}$ & - & 0.52 & 0.54 \\
\hline \multirow{6}{*}{$\begin{array}{l}\text { Knee rigidity } \\
(\mathrm{mm})\end{array}$} & Placebo 1 & $69.30 \pm 31.71$ & $-6.09 \pm 11.97$ & $-5.13 \pm 18.55$ \\
\hline & Placebo 2 & $72.32 \pm 24.29$ & $-11.05 \pm 22.32$ & $-6.55 \pm 20.29$ \\
\hline & Active & $69.75 \pm 29.83$ & $3.83 \pm 14.07$ & $-1.17 \pm 11.00$ \\
\hline & $p^{a}$ & - & 0.061 & 0.75 \\
\hline & $p^{b}$ & - & $0.041^{*}$ & 0.44 \\
\hline & $p^{c}$ & - & $0.047 *$ & 0.86 \\
\hline
\end{tabular}




\begin{tabular}{|c|c|c|c|c|}
\hline & & Week 0 & $\Delta$ week 4 & week 8 \\
\hline \multirow{6}{*}{$\begin{array}{l}\text { Defecation } \\
\text { regularity } \\
(\mathrm{mm})\end{array}$} & Placebo 1 & $55.57 \pm 32.73$ & $-6.09 \pm 18.99$ & $-3.83 \pm 28.32$ \\
\hline & Placebo 2 & $51.95 \pm 37.17$ & $-5.80 \pm 21.69$ & $3.59 \pm 20.02$ \\
\hline & Active & $46.08 \pm 32.07$ & $3.63 \pm 30.04$ & $5.75 \pm 26.08$ \\
\hline & $p^{a}$ & - & 0.42 & 0.37 \\
\hline & $p^{b}$ & - & 0.36 & 0.27 \\
\hline & $p^{c}$ & - & 0.19 & 0.93 \\
\hline \multirow{6}{*}{$\begin{array}{l}\text { Defecation } \\
\text { difficulty } \\
(\mathrm{mm})\end{array}$} & Placebo 1 & $61.91 \pm 33.58$ & $4.87 \pm 27.11$ & $4.52 \pm 26.44$ \\
\hline & Placebo 2 & $63.82 \pm 32.25$ & $-7.05 \pm 23.85$ & $-6.27 \pm 24.08$ \\
\hline & Active & $58.57 \pm 26.44$ & $8.13 \pm 21.62$ & $6.17 \pm 17.54$ \\
\hline & $p^{a}$ & - & 0.18 & 0.17 \\
\hline & $p^{b}$ & - & 0.33 & 0.52 \\
\hline & $p^{c}$ & - & 0.06 & 0.06 \\
\hline \multirow{6}{*}{$\begin{array}{l}\text { Defecation } \\
\text { satisfaction } \\
\qquad(\mathrm{mm})\end{array}$} & Placebo 1 & $67.78 \pm 29.41$ & $7.52 \pm 26.28$ & $4.17 \pm 29.84$ \\
\hline & Placebo 2 & $65.55 \pm 27.72$ & $-1.30 \pm 28.73$ & $-3.32 \pm 16.87$ \\
\hline & Active & $60.46 \pm 27.72$ & $8.83 \pm 28.98$ & $7.00 \pm 16.92$ \\
\hline & $p^{a}$ & - & 0.28 & 0.05 \\
\hline & $p^{b}$ & - & 0.66 & 0.48 \\
\hline & $p^{c}$ & - & 0.15 & $0.008 * *$ \\
\hline
\end{tabular}

Values are shown as the mean \pm standard deviation. The Kruskal-Wallis test was performed to analyze the changes from the baseline (week 0) to weeks 4 and 8 among the three groups $\left(p^{a}\right)$.Mann-Whitney's $\mathrm{U}$ test was performed to analyze changes from the baseline (week 0 ) to weeks 4 and 8 between the active test and placebo 1 food groups $\left(p^{b}\right)$, or the active test and placebo 2 food groups $\left(p^{c}\right)$. $\Delta$ week 4 , the change from baseline to week $4 ; \Delta$ week 8 , the change from baseline to week 8 . *Statistically significant, $\mathrm{p}<0.05$.

\section{Effects of High-Isoflavone Soybeans on Lipid Metabolism Parameters, Transferrin, and Body}

\section{Composition}

We evaluated lipid metabolism parameters (TC, LDL-C, HDL-C, and TG), transferrin (TIBC and UIBC), and body composition (BW, BFP, and BMI) after the ingestion of the test food (Table 7). There were no differences between the active test and Placebo 1 food groups and the active test and Placebo 2 food groups regarding changes in all parameters. 
Table 7. Lipid metabolism parameters, transferrin, and body composition

\begin{tabular}{|c|c|c|c|c|}
\hline & & Week 0 & $\triangle$ week 4 & $\triangle$ week 8 \\
\hline \multirow{6}{*}{$\begin{array}{c}\mathrm{TC} \\
(\mathrm{mg} / \mathrm{dl})\end{array}$} & Placebo 1 & $242.35 \pm 41.09$ & $1.43 \pm 22.64$ & $8.87 \pm 43.44$ \\
\hline & Placebo 2 & $227.91 \pm 29.17$ & $3.05 \pm 15.37$ & $7.86 \pm 16.65$ \\
\hline & Active & $235.25 \pm 28.66$ & $1.92 \pm 12.25$ & $3.29 \pm 15.47$ \\
\hline & $p^{a}$ & - & 0.95 & 0.77 \\
\hline & $p^{b}$ & - & 0.93 & 0.56 \\
\hline & $p^{c}$ & - & 0.79 & 0.34 \\
\hline \multirow{6}{*}{$\begin{array}{l}\text { LDL-C } \\
(\mathrm{mg} / \mathrm{dl})\end{array}$} & Placebo 1 & $150.26 \pm 36.22$ & $0.17 \pm 19.75$ & $3.65 \pm 20.90$ \\
\hline & Placebo 2 & $135.23 \pm 26.18$ & $4.35 \pm 14.69$ & $7.41 \pm 10.91$ \\
\hline & Active & $140.79 \pm 26.86$ & $3.50 \pm 12.09$ & $4.71 \pm 11.96$ \\
\hline & $p^{a}$ & - & 0.65 & 0.70 \\
\hline & $p^{b}$ & - & 0.49 & 0.83 \\
\hline & $p^{c}$ & - & 0.83 & 0.43 \\
\hline \multirow{6}{*}{$\begin{array}{l}\text { HDL-C } \\
(\mathrm{mg} / \mathrm{dl})\end{array}$} & Placebo 1 & $77.00 \pm 22.19$ & $0.35 \pm 8.02$ & $3.26 \pm 10.18$ \\
\hline & Placebo 2 & $80.23 \pm 19.98$ & $3.40 \pm 5.83$ & $6.18 \pm 9.84$ \\
\hline & Active & $84.58 \pm 19.97$ & $0.79 \pm 8.05$ & $3.29 \pm 7.66$ \\
\hline & $p^{a}$ & - & 0.36 & 0.48 \\
\hline & $p^{b}$ & - & 0.85 & 0.99 \\
\hline & $p^{c}$ & - & 0.23 & 0.27 \\
\hline \multirow{6}{*}{$\begin{array}{c}\mathrm{TG} \\
(\mathrm{mg} / \mathrm{dl})\end{array}$} & Placebo 1 & $116.65 \pm 69.37$ & $-0.43 \pm 41.86$ & $-14.91 \pm 30.94$ \\
\hline & Placebo 2 & $87.14 \pm 53.28$ & $-1.05 \pm 42.13$ & $-14.50 \pm 43.69$ \\
\hline & Active & $78.04 \pm 33.17$ & $-1.42 \pm 26.40$ & $-2.88 \pm 16.96$ \\
\hline & $p^{a}$ & - & 1.00 & 0.35 \\
\hline & $p^{b}$ & - & 0.92 & 0.10 \\
\hline & $p^{c}$ & - & 0.97 & 0.23 \\
\hline \multirow{6}{*}{$\begin{array}{l}\text { TIBC } \\
(\mu \mathrm{g} / \mathrm{dl})\end{array}$} & Placebo 1 & $308.35 \pm 34.69$ & $9.83 \pm 23.40$ & $11.87 \pm 22.47$ \\
\hline & Placebo 2 & $322.77 \pm 49.01$ & $14.50 \pm 23.47$ & $13.95 \pm 22.78$ \\
\hline & Active & $326.79 \pm 54.80$ & $3.63 \pm 17.75$ & $9.75 \pm 21.01$ \\
\hline & $p^{a}$ & - & 0.25 & 0.81 \\
\hline & $p^{b}$ & - & 0.31 & 0.74 \\
\hline & $p^{c}$ & - & 0.09 & 0.52 \\
\hline \multirow{4}{*}{$\begin{array}{l}\text { UIBC } \\
(\mu \mathrm{g} / \mathrm{dl})\end{array}$} & Placebo 1 & $191.91 \pm 45.44$ & $5.74 \pm 37.83$ & $13.48 \pm 27.19$ \\
\hline & Placebo 2 & $216.27 \pm 66.48$ & $25.40 \pm 39.02$ & $16.45 \pm 42.71$ \\
\hline & Active & $217.54 \pm 91.56$ & $16.83 \pm 44.91$ & $12.08 \pm 57.25$ \\
\hline & $p^{a}$ & - & 0.29 & 0.94 \\
\hline
\end{tabular}




\begin{tabular}{ccccc} 
& $p^{b}$ & - & 0.37 & 0.92 \\
& $p^{c}$ & - & 0.51 & 0.77 \\
\hline BW & Placebo 1 & $52.59 \pm 10.89$ & $0.28 \pm 0.59$ & $0.30 \pm 0.88$ \\
$(\mathrm{~kg})$ & Placebo 2 & $52.36 \pm 7.01$ & $0.39 \pm 0.60$ & $0.39 \pm 0.68$ \\
& Active & $50.78 \pm 5.99$ & $0.36 \pm 0.65$ & $0.24 \pm 0.72$ \\
& $p^{a}$ & - & 0.85 & 0.81 \\
& $p^{b}$ & - & 0.66 & 0.79 \\
& $p^{c}$ & - & 0.91 & 0.49 \\
\hline BFP & Placebo 1 & $28.92 \pm 7.97$ & $-0.17 \pm 1.66$ & $-0.10 \pm 2.43$ \\
$(\%)$ & Placebo 2 & $31.34 \pm 5.68$ & $0.27 \pm 0.68$ & $0.07 \pm 1.05$ \\
& Active & $28.45 \pm 5.05$ & $0.42 \pm 1.01$ & $0.32 \pm 1.10$ \\
& $p^{a}$ & - & 0.23 & 0.68 \\
& $p^{b}$ & - & 0.15 & 0.44 \\
\hline BMI & $p^{c}$ & - & 0.58 & 0.44 \\
\hline$\left(\mathrm{kg} / \mathrm{m}^{2}\right)$ & Placebo 1 & $21.26 \pm 4.55$ & $0.13 \pm 0.25$ & $0.13 \pm 0.35$ \\
& Placebo 2 & $21.23 \pm 2.60$ & $0.17 \pm 0.23$ & $0.17 \pm 0.29$ \\
& Active & $20.35 \pm 2.29$ & $0.15 \pm 0.27$ & $0.09 \pm 0.30$ \\
& $p^{a}$ & - & 0.88 & 0.69 \\
\hline & $p^{b}$ & - & 0.75 & 0.69 \\
\hline
\end{tabular}

Values are shown as the mean \pm standard deviation. ANOVA was performed to analyze changes from the baseline (week 0) to weeks 4 and 8 among three groups $\left(p^{a}\right)$. Student's t-test was performed to analyze changes in values from the baseline (week 0 ) to weeks 4 and 8 between the active test and placebo 1 food groups $\left(p^{b}\right.$ ), or the active test and placebo 2 food groups $\left(p^{c}\right)$. TC, total cholesterol; LDL-C, low-density lipoprotein cholesterol; HDL-C, high-density lipoprotein cholesterol; TG, triglyceride; TIBC, total iron binding capacity; UIBC, unsaturated iron binding capacity; BW, body weight; BFP, body fat percentage; BMI, body mass index. $\Delta$ week 4 , the change from baseline to week $4 ; \Delta$ week 8 , the change from baseline to week 8 . *Statistically significant, $p<0.05$.

\section{Safety}

We evaluated BP, CBCs, glucose metabolism parameters, liver and renal function, and hormone levels after ingestion of the test foods. As shown in Table 8, minimal changes were observed in BP (SBP and DBP), CBC parameters (WBCs, RBCs, Hb, Ht, and Plt), glucose metabolism parameters (FBG and $\mathrm{HbA1c}$ ), liver function (AST, ALT, $\gamma$-GTP, ALP, and LDH), renal function (BUN, CRE, and UA), hormones ( $\mathrm{E}_{2}$, and FSH). Few subjects exhibited adverse effects (gastrointestinal disorders, $\mathrm{n}=29$; insomnia/agitation, $\mathrm{n}=5$; respiratory disorders, $\mathrm{n}=38$; headache, $\mathrm{n}=28$; vertigo, $\mathrm{n}=5$; fever, $\mathrm{n}=15$ ). These subjects presented only mild symptoms and recovered within a few brief days; therefore, the principal investigator judged that no adverse events were 
related to the ingestion of the test food. These results suggested that the ingestion of high-isoflavone soybean ("Yukipirika") had no or minimal unfavorable effects even at a dose of 8.5 g/day (dry weight soybeans).

Table 8. Blood pressure, CBC parameters, glucose metabolism parameters, liver and renal function, hormone

\begin{tabular}{|c|c|c|c|c|}
\hline & & Week 0 & Week 4 & Week 8 \\
\hline \multirow{3}{*}{$\begin{array}{c}\text { SBP } \\
(\mathrm{mmHg})\end{array}$} & Placebo 1 & $118.88 \pm 20.73$ & $116.92 \pm 18.17$ & $116.52 \pm 19.39$ \\
\hline & Placebo 2 & $117.00 \pm 16.96$ & $112.18 \pm 17.12$ & $114.33 \pm 14.76$ \\
\hline & Active & $117.48 \pm 14.26$ & $114.92 \pm 12.55$ & $116.54 \pm 14.62$ \\
\hline \multirow{3}{*}{$\begin{array}{c}\text { DBP } \\
(\mathrm{mmHg})\end{array}$} & Placebo 1 & $75.88 \pm 12.02$ & $75.00 \pm 11.94$ & $74.52 \pm 11.36$ \\
\hline & Placebo 2 & $73.12 \pm 7.96$ & $71.55 \pm 10.87$ & $73.33 \pm 10.05$ \\
\hline & Active & $73.04 \pm 10.17$ & $72.00 \pm 9.06$ & $73.75 \pm 10.86$ \\
\hline \multirow{3}{*}{$\begin{array}{c}\text { WBCs } \\
\left(\times 10^{3} / \mu \mathrm{l}\right)\end{array}$} & Placebo 1 & $5.17 \pm 1.46$ & $5.06 \pm 1.16$ & $4.94 \pm 1.43$ \\
\hline & Placebo 2 & $4.84 \pm 1.03$ & $4.67 \pm 1.03$ & $4.97 \pm 1.04$ \\
\hline & Active & $5.06 \pm 1.26$ & $5.35 \pm 1.58$ & $5.38 \pm 2.57$ \\
\hline \multirow{3}{*}{$\begin{array}{c}\text { RBCs } \\
\left(\times 10^{4} / \mu 1\right)\end{array}$} & Placebo 1 & $453.08 \pm 35.04$ & $456.67 \pm 33.81$ & $456.09 \pm 37.05$ \\
\hline & Placebo 2 & $441.88 \pm 35.63$ & $442.32 \pm 38.68$ & $443.50 \pm 37.26$ \\
\hline & Active & $458.20 \pm 31.15$ & $453.08 \pm 36.08$ & $455.88 \pm 43.38$ \\
\hline \multirow{3}{*}{$\begin{array}{c}\mathrm{Hb} \\
(\mathrm{g} / \mathrm{dl})\end{array}$} & Placebo 1 & $13.96 \pm 1.04$ & $14.03 \pm 1.08$ & $14.06 \pm 1.12$ \\
\hline & Placebo 2 & $13.38 \pm 1.34$ & $13.20 \pm 1.45$ & $13.33 \pm 1.34$ \\
\hline & Active & $13.62 \pm 1.44$ & $13.35 \pm 1.55$ & $13.46 \pm 1.66$ \\
\hline \multirow{3}{*}{$\begin{array}{l}\mathrm{Ht} \\
(\%)\end{array}$} & Placebo 1 & $42.09 \pm 3.19$ & $42.64 \pm 2.97$ & $42.33 \pm 3.37$ \\
\hline & Placebo 2 & $40.53 \pm 3.58$ & $40.65 \pm 3.86$ & $40.75 \pm 3.59$ \\
\hline & Active & $41.39 \pm 3.59$ & $41.11 \pm 4.00$ & $41.42 \pm 4.41$ \\
\hline \multirow{3}{*}{$\begin{array}{c}\text { Plt } \\
\left(\times 10^{4} / \mu \mathrm{l}\right)\end{array}$} & Placebo 1 & $24.39 \pm 6.55$ & $24.13 \pm 5.01$ & $23.83 \pm 5.73$ \\
\hline & Placebo 2 & $25.51 \pm 4.74$ & $25.56 \pm 5.83$ & $25.79 \pm 5.42$ \\
\hline & Active & $24.26 \pm 6.58$ & $24.41 \pm 6.84$ & $23.88 \pm 6.30$ \\
\hline \multirow{3}{*}{$\begin{array}{c}\text { FBG } \\
(\mathrm{mg} / \mathrm{dl})\end{array}$} & Placebo 1 & $89.13 \pm 9.72$ & $89.29 \pm 8.07$ & $87.78 \pm 8.65$ \\
\hline & Placebo 2 & $84.52 \pm 3.68$ & $85.23 \pm 5.50$ & $85.00 \pm 5.23$ \\
\hline & Active & $85.56 \pm 5.55$ & $85.92 \pm 5.81$ & $85.54 \pm 5.70$ \\
\hline \multirow{3}{*}{$\begin{array}{c}\mathrm{HbA} 1 \mathrm{c} \\
(\%)\end{array}$} & Placebo 1 & $5.31 \pm 0.28$ & $5.38 \pm 0.28$ & $5.33 \pm 0.31$ \\
\hline & Placebo 2 & $5.22 \pm 0.21$ & $5.32 \pm 0.19$ & $5.20 \pm 0.17$ \\
\hline & Active & $5.35 \pm 0.26$ & $5.42 \pm 0.32$ & $5.32 \pm 0.29$ \\
\hline AST & Placebo 1 & $23.21 \pm 5.58$ & $23.63 \pm 6.15$ & $23.13 \pm 5.08$ \\
\hline$(\mathrm{U} / \mathrm{l})$ & Placebo 2 & $23.20 \pm 4.57$ & $23.45 \pm 5.06$ & $22.96 \pm 4.20$ \\
\hline
\end{tabular}




\begin{tabular}{|c|c|c|c|c|}
\hline & & Week 0 & Week 4 & Week 8 \\
\hline & Active & $20.00 \pm 3.44$ & $20.58 \pm 4.56$ & $20.96 \pm 3.79$ \\
\hline \multirow{3}{*}{$\begin{array}{l}\text { ALT } \\
(\mathrm{U} / \mathrm{l})\end{array}$} & Placebo 1 & $21.83 \pm 13.60$ & $23.67 \pm 14.86$ & $20.13 \pm 10.54$ \\
\hline & Placebo 2 & $18.48 \pm 5.02$ & $18.95 \pm 5.92$ & $17.96 \pm 5.24$ \\
\hline & Active & $15.32 \pm 5.02$ & $16.33 \pm 4.69$ & $17.25 \pm 5.48$ \\
\hline \multirow{3}{*}{$\begin{array}{c}\gamma-\mathrm{GTP} \\
(\mathrm{U} / \mathrm{l})\end{array}$} & Placebo 1 & $28.71 \pm 20.17$ & $29.71 \pm 24.10$ & $25.13 \pm 18.79$ \\
\hline & Placebo 2 & $25.12 \pm 10.68$ & $25.09 \pm 11.24$ & $25.79 \pm 13.82$ \\
\hline & Active & $18.84 \pm 5.07$ & $19.21 \pm 5.77$ & $19.33 \pm 7.38$ \\
\hline \multirow{3}{*}{$\begin{array}{l}\text { ALP } \\
(\mathrm{U} / \mathrm{l})\end{array}$} & Placebo 1 & $233.29 \pm 47.37$ & $230.83 \pm 45.23$ & $232.48 \pm 50.24$ \\
\hline & Placebo 2 & $229.24 \pm 42.87$ & $222.14 \pm 38.88$ & $228.00 \pm 45.11$ \\
\hline & Active & $218.96 \pm 71.24$ & $218.04 \pm 69.67$ & $227.29 \pm 70.19$ \\
\hline \multirow{3}{*}{$\begin{array}{l}\text { LDH } \\
(\mathrm{U} / \mathrm{l})\end{array}$} & Placebo 1 & $197.96 \pm 25.23$ & $190.17 \pm 22.72$ & $209.65 \pm 26.02$ \\
\hline & Placebo 2 & $201.92 \pm 25.32$ & $197.68 \pm 26.82$ & $206.83 \pm 24.86$ \\
\hline & Active & $198.64 \pm 32.20$ & $195.00 \pm 27.27$ & $198.67 \pm 28.88$ \\
\hline \multirow{3}{*}{$\begin{array}{c}\text { BUN } \\
(\mathrm{mg} / \mathrm{dl})\end{array}$} & Placebo 1 & $13.81 \pm 2.82$ & $14.19 \pm 2.44$ & $13.67 \pm 1.87$ \\
\hline & Placebo 2 & $14.03 \pm 3.44$ & $15.28 \pm 2.72$ & $14.61 \pm 3.00$ \\
\hline & Active & $14.23 \pm 3.07$ & $14.75 \pm 3.50$ & $15.16 \pm 3.67$ \\
\hline \multirow{3}{*}{$\begin{array}{c}\text { CRE } \\
(\mathrm{mg} / \mathrm{dl})\end{array}$} & Placebo 1 & $0.67 \pm 0.08$ & $0.66 \pm 0.09$ & $0.69 \pm 0.08$ \\
\hline & Placebo 2 & $0.69 \pm 0.09$ & $0.70 \pm 0.08$ & $0.72 \pm 0.09$ \\
\hline & Active & $0.71 \pm 0.11$ & $0.67 \pm 0.09$ & $0.72 \pm 0.10$ \\
\hline \multirow{3}{*}{$\begin{array}{c}\text { UA } \\
(\mathrm{mg} / \mathrm{dl})\end{array}$} & Placebo 1 & $4.73 \pm 0.86$ & $4.94 \pm 1.07$ & $4.75 \pm 1.05$ \\
\hline & Placebo 2 & $4.20 \pm 0.66$ & $4.34 \pm 0.77$ & $4.16 \pm 0.78$ \\
\hline & Active & $4.75 \pm 0.72$ & $4.63 \pm 0.64$ & $4.55 \pm 0.78$ \\
\hline \multirow{3}{*}{$\begin{array}{c}\text { E2 } \\
(\mathrm{pg} / \mathrm{ml})\end{array}$} & Placebo 1 & $24.35 \pm 46.33$ & $26.22 \pm 65.89$ & $32.13 \pm 64.60$ \\
\hline & Placebo 2 & $28.32 \pm 73.49$ & $34.50 \pm 75.82$ & $33.68 \pm 51.90$ \\
\hline & Active & $34.25 \pm 47.93$ & $52.58 \pm 91.61$ & $33.88 \pm 64.24$ \\
\hline \multirow{3}{*}{$\begin{array}{c}\text { FSH } \\
(\mathrm{mIU} / \mathrm{ml})\end{array}$} & Placebo 1 & $72.29 \pm 30.66$ & $72.49 \pm 27.00$ & $69.88 \pm 30.97$ \\
\hline & Placebo 2 & $84.22 \pm 49.01$ & $83.72 \pm 47.88$ & $78.49 \pm 46.75$ \\
\hline & Active & $68.10 \pm 41.03$ & $64.59 \pm 40.50$ & $67.22 \pm 34.17$ \\
\hline
\end{tabular}

Values are shown as the mean \pm standard deviation. SBP, systolic blood pressure; DBP, diastolic blood pressure; WBCs, white blood cells; RBCs, red blood cells; Hb, hemoglobin; Ht, hematocrit; Plt, platelet count; FBG, fasting blood glucose; HbA1c, hemoglobin A1c; AST, aspartate aminotransferase; ALT, alanine aminotransferase; $\gamma$-GTP, gamma glutamyl transpeptidase; ALP, alkaline phosphatase; LDH, lactate dehydrogenase; BUN, blood urea nitrogen; CRE, creatinine; UA, uric acid; E2, estradiol; FSH, follicle-stimulating hormone. 


\section{DISCUSSION}

This clinical trial revealed that high-isoflavone soybeans displayed more beneficial effects on menopausal symptom, skin condition, joints functions, and bowel movements compared to low-isoflavone soybean or wheat in climacteric women.

There were no significant differences between the active test and Placebo 1 food groups and the active test and Placebo 2 food groups regarding changes in total scores of SMI. However, sub-scores from questions 1 to 4 of SMI significantly decreased in the active test group compared to the Placebo 2 group, suggesting an improvement. Questions 1 to 4 assessed the "menopausal symptoms" caused by the reduction in estrogen secretion. The chemical structures of isoflavone are similar to that of estradiol, while compounds of isoflavone appear to exert an estrogenic or anti-estrogenic effect depending on the circulating estrogen levels [10, 21]. Previous clinical studies have reported that 12 weeks of continuous ingestion of $80 \mathrm{mg}$ isoflavone significantly decreased the frequency of hot flashes compared to the ingestion of the placebo food [22]. The levels of E2 and FSH did not change during this clinical study. These facts suggest that the isoflavone contained in the active test food "Yukipirika" did in fact improve "menopausal symptoms".

Urinary NTx, urinary Dpyr, and serum TRACP-5b were not different among the active test food, Placebo 1 food and Placebo 2 food groups in all analyses performed and in each subgroup analysis (pre-/post-menopause). A previous study has shown that 2 weeks of ingesting $25 \mathrm{mg}$ daily of soy isoflavone aglycone significantly decreases Dpyr [23]. However, results of our meta-analysis indicated that the effects of isoflavone intake on osteoporosis are not clear [24]. We need to re-evaluate our intake period and inclusion criteria considered.

The active test food intake tended to improve the score of "skin mat" in the VAS questionnaire compared to Placebo 2 food intake at week 8. Additionally, the score of "skin dryness" in the VAS questionnaire was increased by the ingestion of the active test food compared to Placebo 2 food at week 4 and week 8 . However, "skin acne" was decreased by the ingestion of the active test food compared to Placebo 1 and Placebo 2 food at week 4 . The increase of skin acne by the intake of the active test food might be observed as a result of improvement of "skin dryness." Previous clinical trials suggested that a 12-week intake of soybean hypocotyls significantly improved melanin formation caused by aging [20]. Additionally, soy isoflavone glycitin inhibited skin aging and wrinkles by promoting human dermal fibroblast cell proliferation and migration via transforming growth factor $-\beta$ [25]. All these reports support our data, showing that the isoflavones contained in the active test food improved skin condition in our clinical study. 
The score of "knee pain" in the VAS questionnaire improved in the active test food group compared to the Placebo 1 food group at weeks 4 and 8 . Moreover, the intake of the active test food increased "knee rigidity" compared to the Placebo 2 and Placebo 1 food groups at week 4. Knee osteoarthritis (OA) is a progressive joint disease that serves as one of the primary causes of physical disability with advancing age [26, 27]. The goal of OA treatment is to reduce symptoms and slow disease progression [28]. Natural compounds such as chondroitin and glucosamine are used for OA medicine. It was reported that oxidative stress is related to the progression of OA [29], while isoflavones display anti-oxidative effects [30, 31]. Moreover, it has been reported that genistein and daidzein suppressed inflammation in animal models of rheumatoid arthritis [32]. This fact suggests that the intake of high-isoflavone soybeans improves OA symptoms via antioxidants and anti-inflammation. Nevertheless, further clinical trials are required to test subjects with knee pain for the effects of high-isoflavone soybeans on OA.

Active test food intake improved the score of "Defecation difficulty" in the VAS questionnaire compared to Placebo 2 food intake at weeks 4 and 8. Additionally, the score of "Defecation satisfaction" was improved by ingestion of the active test food compared to the ingestion of Placebo 2 food at week 8. This fact suggests that the intake of high-isoflavone soybeans improved bowel movement. The isoflavone daidzein is metabolized to equol by intestinal bacteria [33]. However, the research on the effect of isoflavone and its metabolite to intestinal flora was limited. Further clinical trials are required to subjects with constipation for the effects of high-isoflavone soybeans on intestinal flora.

\section{CONCLUSION}

The results of this study revealed that high-isoflavone soybeans improved the menopausal symptoms of climacteric women. Furthermore, high-isoflavone soybeans had positive effects on skin conditions, joints functions, and bowel movements. In an aging society like Japan, it is important to research and develop foods that are rich with nutrients and functional components, which can continue to address these problems. Although further clinical trials with long-intake period of high-isoflavone soybean diet are required, the present study promotes the development of new applications of isoflavone-enriched food using the high-isoflavone soybean "Yukipirika".

List of Abbreviations: ALT, alanine aminotransferase; ALP, alkaline phosphatase; AST, aspartate aminotransferase; BP, blood pressure; BUN, blood urea nitrogen; BFP, body fat percentage; BMI, body mass index; BW, body weight; CBCs, complete blood counts; CRE 
creatinine; DBP, diastolic blood pressure; Dpyr, deoxypyridinoline; E2, estradiol; FBG, fasting blood glucose; FSH, follicle-stimulating hormone; $\gamma$-GTP, gamma glutamyl transpeptidase; Ht, hematocrit; $\mathrm{Hb}$, hemoglobin; HbA1c, hemoglobin A1c; HDL-C, high-density lipoprotein cholesterol; LDH, lactate dehydrogenase; LDL-C, low-density lipoprotein cholesterol; RBCs, red blood cells; SBP, systolic blood pressure; SMI, simplified menopausal index; Plt, platelet count; TRACP-5b, tartrate-resistant acid phosphatase-5b; TC, total cholesterol; TIBC, total iron binding capacity; TG, triglycerides; NTx, type I collagen cross-linked N-telopeptide; UIBC, unsaturated iron binding capacity; UA, uric acid; VAS, visual analog scale; WBCs, white blood cells.

Author Contributions: J.N., M.N., M.S. and M.K. designed the research. M.S. and M.K. provided test food. J.N. conducted the research. M.N. performed statistical analyses. M.N. and J.N. wrote the manuscript. J.N. had primary responsibility for the final content. All authors read and approved the final version of the manuscript.

Competing Interests: There are no conflicts of interest to declare.

Acknowledgements and Funding: We are deeply grateful to Ishiguro T. (Asahimatsu Foods Co., Ltd., Nagano, Japan) for soy bean flake production and Nakao Y. (Nippon Food Manufacturer, Hokkaido, Japan) for wheat flake production. Additionally, we thank the members of Hokkaido Information University, Center of Health Information Science Research (Anzai Y., Fukuda Y., Ito M., Kamo S., Koyama S., Miyao A., Obata N., Ohkubo Y., Ohshima M., Saito T., Saito Y, Sasaki M., Sato K., Shima N., Tanaka A., Teramoto M., Tsunemine S.) for their technical assistance with the clinical trial. This work was supported by a grant from the Research Project on the Development of Functional Foods Produced in Hokkaido (Hokkaido, Japan).

\section{REFERENCES}

1. Nelson HD: Menopause. Lancet 2008, 371:760-770.

2. Takahashi TA, Johnson KM: Menopause. Med Clin North Am 2015, 99:521-534.

3. Canderelli R, Leccesse LA, Miller NL, Unruh Davidson J: Benefits of hormone replacement therapy in postmenopausal women. J Am Acad Nurse Pract. 2007, 19:635-641. 
4. Weber M, Mapstone M: Memory complaints and memory performance in the menopausal transition. Menopause 2009, 16:694-700.

5. Kannel WB, Hjortland MC, Mcnamara PM, Gordon T: Menopause and risk of cardiovascular disease: the Framingham study. Ann Intern Med 1976, 85:447-452.

6. Lindsay R: Hormones and bone health in postmenopausal women. Endocrine. 2004, 24:223-230.

7. Candore G, Balistreri CR, Grimaldi MP, Vasto S, Listì F, Chiappelli M, Licastro F, Lio D, Caruso C: Age-related inflammatory diseases: role of genetics and gender in the pathophysiology of Alzheimer's disease. Ann N Y Acad Sci 2006, 1089:472-486.

8. Xu LW, Jia M, Salchow R, Kentsch M, Cui XJ, Deng HY, Sun ZJ, Kluwe L: Efficacy and side effects of chinese herbal medicine for menopausal symptoms: a critical review. Evid Based Complement Alternat Med 2012, 2012:568106.

9. Kuiper GG, Lemmen JG, Carlsson B, Corton JC, Safe SH, Van Der Saag PT, Van Der Burg B, Gustafsson JA: Interaction of estrogenic chemicals and phytoestrogens with estrogen receptor beta. Endocrinology 1998, 139:4252-4263.

10. Anderson JJ, Anthony MS, Cline JM, Washburn SA, Garner SC: Health potential of soy isoflavones for menopausal women. Public Health Nutr 1999, 2:489-504.

11. Krebs EE, Ensrud KE, Macdonald R, Wilt TJ: Phytoestrogens for treatment of menopausal symptoms: a systematic review. Obstet Gynecol 2004, 104:824-836.

12. Lagari VS, Levis S: Phytoestrogens in the prevention of postmenopausal bone loss. J Clin Densitom 2013, 16:445-449.

13. Chen MN, Lin CC, Liu CF: Efficacy of phytoestrogens for menopausal symptoms: a meta-analysis and systematic review. Climacteric 2015, 18:260-269.

14. Arai Y, Watanabe S, Kimira M, Shimoi K, Mochizuki R, Kinae N: Dietary intakes of flavonols, flavones and isoflavones by Japanese women and the inverse correlation between quercetin intake and plasma LDL cholesterol concentration. J Nutr 2000, 130:2243-2250.

15. Messina M: A brief historical overview of the past two decades of soy and isoflavone research. J Nutr 2010, 140:1350S-1354S.

16. Messina M: Soy and Health Update: Evaluation of the Clinical and Epidemiologic Literature. Nutrients 2016, 8:E754.

17. Tanifuji K, Miyoshi T, Suzuki C, Tanaka Y, Kato J, Shirai S: Effect of temperature during the seed-filling period and varietal differences in soybean isoflavone content 
and components in cold districts[in Japanese]. Jpn J Crop Sci 2009, 78: 74-82.

18. Koyama T. Simplified menopausal index [in Japanese]. Obstetrical and Gynecological Therapy 1998, 76:756-759.

19. Gupta PK, Chullikana A, Rengasamy M, Shetty N, Pandey V, Agarwal V: Efficacy and safety of adult human bone marrow-derived, cultured, pooled, allogeneic mesenchymal stromal cells (Stempeucel®): preclinical and clinical trial in osteoarthritis of the knee joint. Arthritis Res Ther 2016, 18:301.

20. Maebuchi M, Yonemoto H, Baba T, Miura N: Soybean jypocotyl intake improves scalp hair and skin conditions. Jpn Pharmacol Ther 2015, 43:977-986.

21. Bingham SA, Atkinson C, Liggins J, Bluck L, Coward A: Phyto-oestrogens: where are we now? Br J Nutr 1998, 79:393-406.

22. Van De Weijer PH, Barentsen R: Isoflavones from red clover (Promensil) significantly reduce menopausal hot flush symptoms compared with placebo. Maturitas 2002, 42:187-193.

23. Uesugi S, Watanabe S, Ishiwata N, Uehara M, Ouchi K: Effects of isoflavone supplements on bone metabolic markers and climacteric symptoms in Japanese women. Biofactors 2004, 22:221-228.

24. Sacks FM, Lichtenstein A, Van Horn L, Harris W, Kris-Etherton P, Winston M: American Heart Association Nutrition Committee. Soy protein, isoflavones, and cardiovascular health: an American Heart Association Science Advisory for professionals from the Nutrition Committee. Circulation 2006, 113:1034-1044.

25. Kim YM, Huh JS, Lim Y, Cho M: Soy Isoflavone Glycitin (4'-Hydroxy-6-Methoxyisoflavone-7-D-Glucoside) Promotes Human Dermal Fibroblast Cell Proliferation and Migration via TGF- $\beta$ Signaling. Phytother Res 2015, 29:757-769.

26. Flouzat-Lachaniette CH, Roubineau F, Heyberger C, Bouthors C: Distraction to treat knee osteoarthritis. Joint Bone Spine 2017, 84:141-144.

27. Bijlsma JW, Berenbaum F, Lafeber FP: Osteoarthritis: an update with relevance for clinical practice. Lancet 2011, 377:2115-2126.

28.Roman-Blas JA, Mediero A, Tardío L, Portal-Nuñez S, Gratal P, Herrero-Beaumont G, Largo R: The combined therapy with chondroitin sulfate plus glucosamine sulfate or chondroitin sulfate plus glucosamine hydrochloride does not improve joint damage in an experimental model of knee osteoarthritis in rabbits. Eur J Pharmacol 2017, 
794:8-14.

29. Grover AK, Samson SE: Benefits of antioxidant supplements for knee osteoarthritis: rationale and reality. Nutr J 2016, 15:1.

30. Kao TH, Chen BH: Functional components in soybean cake and their effects on antioxidant activity. J Agric Food Chem 2006, 54:7544-7555.

31. Wang Q, Ge X, Tian X, Zhang Y, Zhang J, Zhang P: Soy isoflavone: The multipurpose phytochemical (Review). Biomed Rep 2013, 1:697-701.

32. Mohammad-Shahi M, Haidari F, Rashidi B, Saei AA, Mahboob S, Rashidi MR: Comparison of the effects of genistein and daidzein with dexamethasone and soy protein on rheumatoid arthritis in rats. Bioimpacts 2011, 1:161-170.

33. Atkinson C, Newton KM, Bowles EJ, Yong M, Lampe JW: Demographic, anthropometric, and lifestyle factors and dietary intakes in relation to daidzein-metabolizing phenotypes among premenopausal women in the United States. Am J Clin Nutr 2008, 87:679-687. 